\title{
El Chafariz, manantial emblemático de Lanzarote
}

\author{
El Chafariz, the emblematic spring of Lanzarote \\ Jiménez-Díaz $\mathrm{JF}^{(1)}$, Hernández-Martínez $\mathrm{FJ}^{(2)}$, Rodríguez-de Vera $\mathrm{BC}^{(1)}$, \\ Jiménez-Rodríguez $\mathrm{C}^{(1)}$ \\ (1)Universidad de Las Palmas de Gran Canaria, Canarias, España \\ ${ }^{(2)}$ Cabildo Insular de Lanzarote, Lanzarote, España \\ juanfernando.jimenez@ulpgc.es
}

\section{Resumen}

Chafariz, es una palabra aborigen que significa fuente o manantial de agua. Ubicado en el Macizo de Famara, en el municipio de Haría, constituye el manantial de agua dulce más importantes de Lanzarote. "El Chafariz", de propiedad particular, siempre fue un recurso de utilización general por la población de Lanzarote que accedía al mismo para aprovisionarse de dicho elemento utilizando para su transporte los animales tradicionales de carga en la isla conejera, los burros y los camellos. El acceso a dicho manantial es a través de galerías, que son túneles excavados que buscan la zona saturada de agua, con pendiente ligeramente ascendente según el avance de la excavación para que el agua fluya por gravedad. Concretamente, el de Famara es un macizo de basalto, donde existen unos diques (inyecciones de magma en la roca madre, que son de alta impermeabilidad) y el agua va acumulándose sobre ellos (agua colgada), así. rompiendo estos diques, el agua emana por gravedad o se canaliza al exterior. Cuando la presión del agua se vuelve demasiado alta, el agua tiende a salir en esta zona de contacto, formando nacientes. La primera galería en Famara se comenzó a perforar por parte del Cabildo Insular en el año 1926. Las galerías de mayor importancia datan de los años cincuenta y sesenta del siglo XX. La primera de las galerías de Famara, que estaba perforada en 1926, está situada en el Barranco del Rincón de la Paja a unos $100 \mathrm{~m}$ de altura y tiene una longitud de 1 $\mathrm{km}$. El agua que se obtenía de las galerías de Famara se canalizaba hasta la capital de la isla, la ciudad de Arrecife, mediante una tubería de conducción que se inauguró en 1953. Su caudal era de unos $1.000 \mathrm{~m} 3 /$ día y se depositaba en las Maretas del Estado. Existían limitaciones de uso del agua subterránea porque por la sobreexplotación del acuífero fue perdiendo su calidad hasta convertirse en salobre.

Palabras clave: Chafariz, manantial, Lanzarote

Key words: Chafariz. spring. Lanzarote 


\section{Referencias}

Avellaner, J.A., J.C. Lavandeira (1993): Lanzarote. Agua, energía y vida. Inalsa. Arrecife.

Bravo, T. (1961): informe hidrológico de la zona norte de la isla de Lanzarote (Acantilado de Famara-Guatifay- El risco y sus dependencias). Arrecife. [Archivo Histórico del Ayuntamiento de Teguise].

Chamorro (1951): Plan de riegos e industrialización de las islas de Lanzarote y Fuerteventura. Santa Cruz de Tenerife.

González Morales, A. (1991): "Aprovechamiento de las aguas y sistemas de riego en Fuerteventura". V Jornadas de Estudios sobre Fuerteventura y Lanzarote.Arrecife. Páginas 13-39.

Hernández Hernández, P., M. Padrón Hernández (1999): "Geografía de Canarias, Hidrografía". En: Hernández Hernández, P. (Editor): Natura y Cultura de las Islas Canarias. La Laguna. Páginas 41-52.

Macías Hernández, A.M. (2001): "De Jardín de las Hespérides a "Islas Sedientas". Por una historia del agua de Canarias, C. 1400-1990". En: Barciela López, C, J. Melgarijo Moreno (Editores): El agua en la historia de España. Salamanca. Páginas 169-271.

Martín Ruíz, J.F. (2001): "Hidrogeografía y recursos humanos". En: Cabildo de Gran Canaria (Editor): Geografía de Canarias. Sociedad y Medio Ambiente. Las Palmas. Páginas 121-158.

Montelongo Fránquiz, A., M.A. Palero Lemes, (2000): "El agua en Arrecife, condicionante histórico". IX Jomadas de Estudios sobre Fuerteventura y Lanzarote. Arrecife. Páginas 161-172. 